\title{
Indulgence Mutations in Cancer Cells
}

\author{
Vladimir N Pak* \\ Freelance researcher, Toronto, Canada
}

Submission: October 04, 2018; Published: October 12, 2018

"Correspondence Address: Vladimir N Pak, Freelance researcher, Toronto, Canada, Email: oncoshut@gmail.com

Keywords: Mutations; Myeloid-derived suppressor cells; Alpha-fetoprotein receptor; MHC class I; CD47; PD-L1; Immunotherapy

Abbreviations: AFP: Alpha-Fetoprotein; AFPR: Alpha-Fetoprotein Receptor; MHC: Major Histocompatibility Complex; MDSC: Myeloid-Derived Suppressor Cells; $\beta 2 \mathrm{M}$ : $\beta 2$-Microglobulin;

\section{An indulgence: "a way to Reduce the Amount of} Punishment one has to undergo for sins."

Mutations in DNA are inevitable part of our life and come at random. With each cell division they are generated and accumulated and some of them can cause cancer. All genes in all positions in the genome can be mutated and then that can give them some advantage, so that they will start proliferating, growing, and building the body of a cancer. Several classes of genes need to be mutated for cancer to progress. These are tumor-suppressors (e.g. p53), genes that protect our cells from cancer, so they need to be inactivated by mutations, and oncogenes. A relatively consistent small number of such mutated genes is required to convert a single normal cell into a cancer cell. Mutations that drive cancer progression are called 'drivers' and the numerous others are called 'passengers'. Mutations that alter the function of driver genes by changing DNA nucleotides have been recognized as key players in cancer progression [1]. It was found that about four mutations per patient on average drive liver cancers, whereas colorectal cancers typically require 10 or so driver mutations. On average, 1 to 10 mutations are needed for cancer to emerge. The number of mutations driving cancer varies considerably across different cancer types [2]. Many of these driver genes are not yet identified and they will be the target for further searching in the future.

We should start thinking about mutations in cancer cells from a very different standpoint than we used to. There are two main mechanisms that protect majority of people from cancer cells growth: programmed cell death (apoptosis) and immune system. A lot is known about mutations in genes of apoptosis pathways, e.g. p53 protein, $\mathrm{Bcl} 2 / \mathrm{Bax}$, caspases; but less is known about cancer cell mutations that affect immune system. The progress in the field of cancer immunotherapy has renewed the urgency of the need for basic studies of immunoregulation. Cancer cells are more than a mass of cells growing out of control; they participate in active battle with the immune system for their own survival. Being able to evade the immune system is a hallmark of cancer. Hence, together with the 'drivers' mutations that helps cancer cells to proliferate there should be additional obligatory 'indulgence' mutations which help them withstand at immune system selection pressure.

Tumors are difficult to destroy because they have a variety of defenses, including an ability to secrete proteins that disable the immune system. Overcoming those defenses has been a major focus of cancer biology research. There are processes like pregnancy, inflammation, antibody overproduction, etc. where immune reactions should be modulated or canceled. Cancer cells accumulate indulgence mutations that exploit these normal immune reactions 'at a wrong time and in a wrong place'. These mutations don't damage apoptosis pathways genes (like p53) but instead upregulate expression of genes that are involved in immune suppression. For example, cancer cells can activate genes of oncofetal proteins that are involved in immune tolerance during pregnancy [3]. Several cancers can re-express embryo secreted alpha-fetoprotein (AFP). AFP can attract myeloid-derived suppressor cells (MDSC) and T-regulatory cells which have specific AFP-binding CCR5 receptor [4-6]. Those top regulatory immune suppressor cells migrate to provide indulgence to tumor cells in its microenvironment. Mutation that allows to re-express AFP can be attributed to indulgence mutation in cancer cell.

Mutations are random and hence, AFP re-expressing cancer cells can do not necessarily express AFP receptor (AFPR) [7]. AFPR re-expression is known for $>80 \%$ of cancers and is more important and critical for cancer cells survival than AFP because the last one can be secreted by the host during inflammation, haemopoiesis or regeneration. Naturally AFP-AFPR nutrient delivery system serves to embryo cells and MDSC which generate immune tolerance during pregnancy [8]. Mutations that lead to reexpression of AFPR are indulgence mutations because they enable cancer cells to share host or self-secreted AFP with AFPR-positive MDSC and T-regulatory cells which can generate protection shield from both innate and adaptive immunities attack [9]. There are 
two major arms of the immune system: innate and adaptive. AFPR re-expressed by cancer cells can suppress both because MDSC are the top regulatory immune suppressors. Nevertheless, there are cases were cancer cells mutations can inactivate separately innate and adaptive immunity executive cells. For example, major histocompatibility complex class (MHC class I) is an important component of adaptive immunity $\mathrm{T}$ and $\mathrm{B}$ cells. Most cells of the body express MHC class I on their surfaces. Due to indulgence mutations human cancer cells can reduce the levels of MHC class I on their surfaces to escape destruction by T cells [10].

Innate immunity natural killer cells and macrophages can be suppressed by the proteins generated by cancer cells. Nearly all cancer cells express high levels of a molecule called CD47 on their surfaces. CD47 expressed on the surfaces of aggressive cancers is a "don't eat me" signal for innate immune cells macrophages. CD47 binds to a SIR alpha protein on the surface of macrophages, inhibiting their ability to kill the cancer cells [11]. MHC class I plays a central role in controlling the phagocytic function of innate immunity macrophages. Cancer cells which MHC class I expression is not reduced can escape from macrophages by capitalizing on their surface the second "don't eat me" signal: the common MHC class I component $\beta 2$-microglobulin $(\beta 2 \mathrm{M})$ that directly protected them from phagocytosis [11].

Cancer cells that do not express MHC class I on their surfaces can be destroyed by natural killer cells and macrophages. To survive, cancer cells can secrete tumor growth factor $\beta$ (TGF- $\beta$ ) [12]. Cancers can suppress the immune system in systemic way: they not only express PD-L1 on their surface but also release a lipid-encapsulated exosome armed with PD-L1 proteins [13]. PD-L1 proteins can directly bind to and inhibit PD-1 protein expressing $\mathrm{T}$ cells - the base of the modern immunotherapy drugs. A single tumor cell can secrete many copies of exosomes and the interaction between the PD-L1 exosomes and T cells in circulation provides a systemic suppression of anti-tumor immunity in the whole body.

Our goal is to kill cancer cells whatever mutations they have accumulated. Against cancer cells having mutations in apoptosis pathway we can use targeted chemotherapy loaded with the toxin that acts on e.g. mitochondria. Mitochondrion or other organelles membrane disruption leads to inevitable cancer cell death because this process is independent of the disabled p53. Against cancer cells with indulgence mutations we can use for example, AFP-toxin drugs [14] that depletes the top immune suppression regulatory MDSC and T-regulatory cells unleashing subordinate both adaptive and innate immune executive cells to erase any cancer cells including metastases - the unsolved problem of oncology today. The future studies will identify even more indulgence mutations in cancer cells which will give us additional targets for cancer gene- and immunotherapy.

\section{References}

1. Chen Y-C, Gotea V, Margolin G, Elnitski L (2017) Significant associations between driver gene mutations and DNA methylation alterations across many cancer types. PLoS Comput Biol 13(11): e1005840.

2. Martincorena I, Raine KM, Gerstung M, Dawson KJ, Haase K, et al. (2017) Universal patterns of selection in cancer and somatic tissues. Cell 171(5): 1029-1041.

3. Pak VN, Belyaev NN (2016) Alpha-fetoprotein-mediated immune tolerance and its reversal. In: Alpha-fetoprotein: Functions and Clinical Applications. Nova Science Publishes, New York, USA, pp. 353-374.

4. Umansky V, Blattner C, Gebhardt C (2017) CCR5 in recruitment and activation of myeloid-derived suppressor cells in melanoma. Cancer Immunol Immunother 66: 1015.

5. Atemezem A, Mbemba E, Marfaing R (2002) Human alpha-fetoprotein binds to primary macrophages. Biochem Biophys Res Commun 296(3): 507-514.

6. Zubkova E, Semenkova L, Dudich E (2013) Alpha-fetoprotein contributes to THP-1 cell invasion and chemotaxis via protein kinase and Gi-protein-dependent pathways. Molecular and Cellular Biochemistry 379(1-2): 283-293.

7. Pak VN (2017) The use of alpha-fetoprotein for treatment of autoimmune diseases and cancer. Ther Deliv 9(1): 37-46.

8. Ostrand-Rosenberg S, Sinha P, Figley C (2017) Frontline Science: Myeloid-derived suppressor cells (MDSCs) facilitate maternal-fetal tolerance in mice. J Leukoc Biol 101(5): 1091-1101.

9. Pak VN (2017) Cancer is the innate immunity fault. Canc Therapy \& Oncol Int J 6(3): 555687.

10. Fruci D, Benevolo M, Cifaldi L, Lorenzi S, Monaco EL, et al. (2012) Major histocompatibility complex class 1 and tumour immuno-evasion: how to fool T cells and natural killer cells at one time. Current Oncology 19(1): 39-41.

11. Barkal AA, Weiskopf K, Kao KS (2018) Engagement of MHC class I by the inhibitory receptor LILRB1 suppresses macrophages and is a target of cancer immunotherapy. Nature Immunology 19: 76-84.

12. Dahmani A, Delisle J-S (2018) TGF- $\beta$ in T Cell Biology: Implications for Cancer Immunotherapy. Cancers 10(6): 194.

13. Chen G, Huang AC, Zhang W (2018) Exosomal PD-L1 contributes to immunosuppression and is associated with anti-PD-1 response. Nature 560: 382-386.

14. Pak VN (2018) Selective targeting of myeloid-derived suppressor cells in cancer patients through AFP-binding receptors. Future Sci. 
This work is licensed under Creative Commons Attribution 4.0 License

DOI: 10.19080/CTOIJ.2018.12.555840
Your next submission with Juniper Publishers will reach you the below assets

- Quality Editorial service

- Swift Peer Review

- Reprints availability

- E-prints Service

- Manuscript Podcast for convenient understanding

- Global attainment for your research

- Manuscript accessibility in different formats ( Pdf, E-pub, Full Text, Audio)

- Unceasing customer service

Track the below URL for one-step submission https://juniperpublishers.com/online-submission.php 